\title{
IN VITRO STUDIES WITH CEFAZAFLUR AND OTHER PARENTERAL CEPHALOSPORINS
}

\author{
Paul actor, Joseph R. Guarini, Joseph Uri, Henry F. Bartus, \\ IHOR ZAJAC and JERRY A. WEISBACH \\ Research and Development Division \\ Smith Kline \& French Laboratories \\ Philadelphia, Pennsylvania 19101, U.S.A.
}

(Received for publication June 10, 1977)

\begin{abstract}
Cefazaflur has a broad-spectrum of in vitro antibacterial activity equal to or greater than that of the commercially-available cephalosporins. In addition, cefazaflur has activity against isolates of Enterobacter, Citrobacter and indole-positive Proteus; however, this activity decreased markedly when the MIC determinations were carried out with a large inoculum size. A similar inoculum effect was observed with cefamandole, however, cefoxitin's activity was relatively unchanged at increased inoculum sizes. Human serum had a relatively small effect on the in vitro activity of cefazaflur.
\end{abstract}

Cefazaflur, a new cephalosporin for parenteral administration is currently under clinical investigation. This cephalosporin has been reported to have potent and broad-spectrum in vitro and in vivo activity when compared with

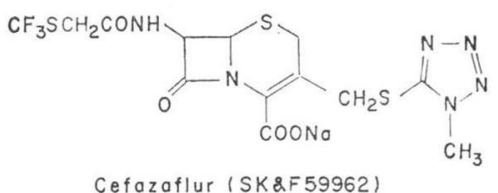

Cefazaflur (SK2F59962)

the commercially-available cephalosporins. ${ }^{1,6)}$ Its spectrum of activity is somewhat broader than the available cephalosporins. ${ }^{1,2,5,11)}$ It is highly stable to the activity of $\beta$-lactamases produced by staphylococci ${ }^{7}$. Cefazaflur has been reported to have good activity against anaerobic bacteria but was less active than cefoxitin against Bacteroides fragilis ${ }^{10)}$. Cefazaflur is bound to serum proteins to about the same extent as is cephalothin, however, serum levels and half-life and urinary recovery, after parenteral administration, are somewhat greater than that of cephalothin ${ }^{3,4,9)}$. Intramuscular administration of cefazaflur is less painful than that produced by cephalothin ${ }^{3)}$.

These studies were in part presented at the 16th Interscience Conference on Antimicrobial Agents and Chemotherapy and deal with the effect of human serum and inoculum size on the activity of cefazaflur. ${ }^{2}$

\section{Materials and Methods}

Approximately 500 isolates of bacteria were employed. The organisms were obtained as clinical isolates from various geographical locations in the United States and are part of the SK\&F culture collection. The inoculum for each experiment was prepared from an appropriate dilution of a log phase culture grown in Trypticase Soy broth. All of the studies were carried out with a single batch of Mueller-Hinton broth. The minimum inhibitory concentrations (MIC) were determined by a semiautomated Microtiter broth dilution technique (Cooke Engineering Co.). Serial two-fold dilutions of antibiotics were prepared in MUELLER-HINTON broth. The final inoculum size, unless otherwise stated, was approximately $10^{5}$ organisms $/ \mathrm{ml}$ test medium. For Streptococcus pyogenes and Streptococcus pneumoniae, ToDD-HewitT broth with an inoculum size of approximately $10^{7}$ organisms $/ \mathrm{ml}$ 
was employed. The Microtiter plates (Cooke Engineering Co.) were incubated overnight in ambient air at $37^{\circ} \mathrm{C}$. The MIC was defined as the lowest concentration of antibiotic in which there was no visible growth. MIC values were determined in separate experiments with and without human serum in the test medium. The inactivated, pooled batch of serum when added to the medium constituted $50 \%$ of the final test medium.

Cefazolin (SK\&F), cephalothin (Lilly), cephapirin (Bristol), and cephaloridine (Lilly) were obtained as commercial preparations. Cefazaflur and cefamandole were prepared in our laboratory and the other experimental cephalosporins were kindly supplied as research samples (cefoxitin, Merck; cefuroxime, Glaxo).

\section{Results and Discussion}

Table 1 summarizes the minimum inhibitory concentrations (MIC) obtained with cefazaflur and commercially-available parenteral cephalosporins against 488 bacterial clinical isolates. Cefazaflur showed excellent activity against the gram-positive bacteria with the median MIC values all below $1 \mathrm{mcg} / \mathrm{ml}$. Fig. 1 plots the cumulative percent of penicillin-sensitive and penicillin-resistant staphylococci inhibited by the four cephalosporins studied. All the cephalosporins showed comparable activity against the staphylococci except for cephaloridine which was more active than the others against penicillin-sensitive Staphylococcus aureus.
Fig. 1. In vitro activity of selected cephalosporins against 100 clinical isolates of Staphylococcus aureus

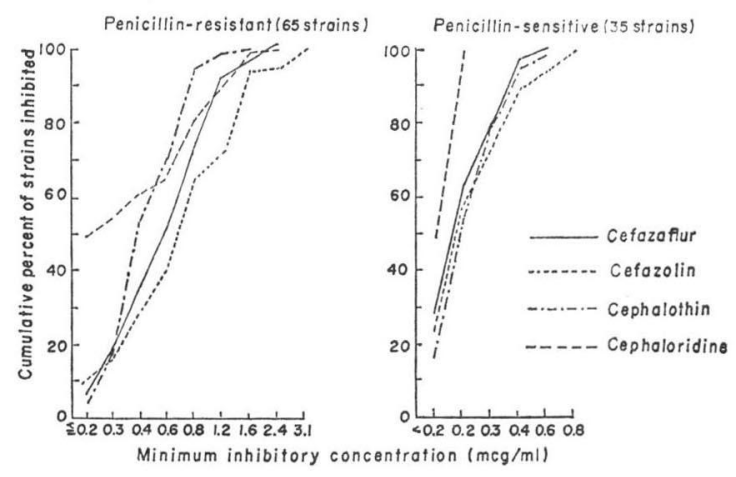

Table 1. Activity of cephalosporins against bacterial clinical isolates

\begin{tabular}{|c|c|c|c|c|c|}
\hline \multirow{2}{*}{ Bacterial species } & \multirow{2}{*}{$\begin{array}{l}\text { No. } \\
\text { isolates }\end{array}$} & \multicolumn{4}{|c|}{ Median minimum inhibitory concentration $(\mathrm{mcg} / \mathrm{ml})$} \\
\hline & & Cefazaflur & Cefazolin & Cephalothin & Cephaloridine \\
\hline $\begin{array}{l}\text { S. aureus } \\
\text { (penicillin-sensitive) }\end{array}$ & 35 & 0.3 & 0.3 & 0.2 & 0.2 \\
\hline $\begin{array}{l}\text { S. aureus } \\
\text { (penicillin-resistant) }\end{array}$ & 65 & 0.6 & 0.8 & 0.4 & 0.3 \\
\hline Strep. pyogenes & 35 & 0.16 & 0.16 & 0.16 & 0.02 \\
\hline Strep. pneumoniae & 10 & 0.16 & 0.10 & 0.24 & 0.08 \\
\hline E. coli & 79 & 0.4 & 1.6 & 6.3 & 3.1 \\
\hline K. pneumoniae & 68 & 0.6 & 1.6 & 3.1 & 4.7 \\
\hline P. mirabilis & 48 & 1.2 & 3.1 & 4.7 & 6.3 \\
\hline Salmonella sp. & 24 & 0.4 & 1.6 & 3.1 & 3.1 \\
\hline Ent. aerogenes & 11 & 1.6 & 3.1 & 25 & 75 \\
\hline Ent. cloacae & 49 & 6.3 & 200 & 200 & 200 \\
\hline Enterobacter sp.* & 10 & 9.4 & $>200$ & 200 & $>200$ \\
\hline Citrobacter & 10 & 28 & 250 & 63 & 220 \\
\hline Proteus rettgeri & 10 & 125 & 500 & 500 & 500 \\
\hline Proteus vulgaris & 10 & 187 & 250 & 250 & 187 \\
\hline Proteus morganii & 10 & 500 & 250 & $>500$ & 500 \\
\hline Herellea & 4 & 312 & 375 & 312 & 156 \\
\hline Providencia & 10 & 375 & $>500$ & 500 & 500 \\
\hline
\end{tabular}

* Seven isolates of E. liquefaciens, 2 E. agglomerans, 1 E. hafniae. 
Fig. 2. In vitro activity of selected cephalosporins against 79 clinical isolates of Escherichia coli

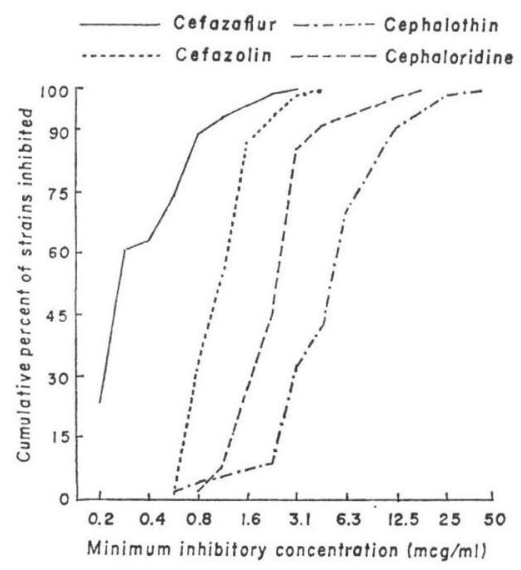

Fig. 4. In vitro activity of selected cephalosporins against 48 clinical isolates of Proteus mirabilis

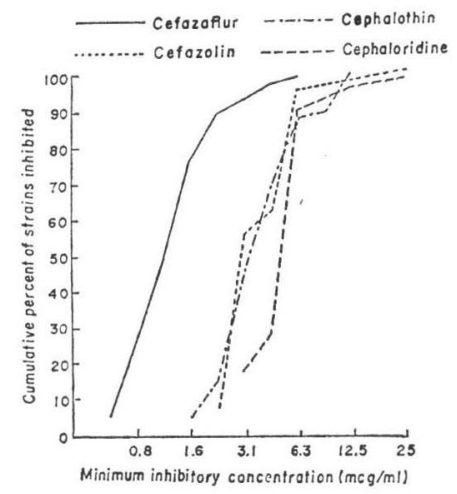

Fig. 3. In vitro activity of selected cephalosporins against 68 clinical isolates of Klebsiella pneumoniae

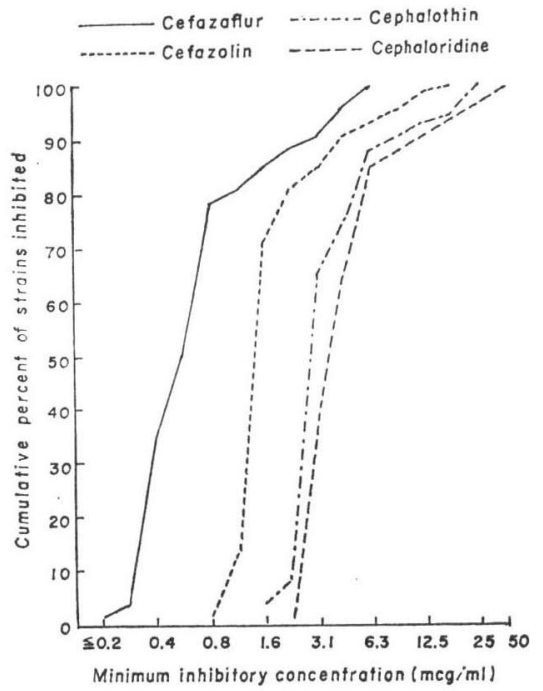

Fig. 5. In vitro activity of selected cephalosporins against 49 clinical isolates of Enterobacter cloacae

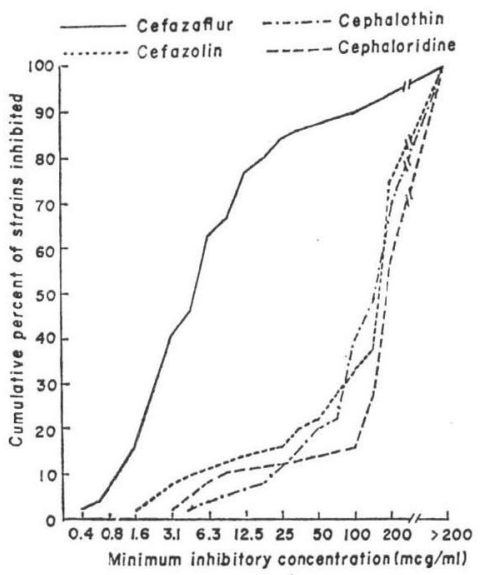

Table 2. Effect of human serum on activity of selected cephalosporins

\begin{tabular}{|c|c|c|c|c|c|c|c|c|c|}
\hline \multirow{3}{*}{ Bacteria } & \multirow{3}{*}{$\begin{array}{l}\text { No. } \\
\text { strains }\end{array}$} & \multicolumn{8}{|c|}{ Median MIC values $(\mathrm{mcg} / \mathrm{ml})$} \\
\hline & & \multicolumn{2}{|c|}{ Cefazaflur } & \multicolumn{2}{|c|}{ Cefazolin } & \multicolumn{2}{|c|}{ Cephalothin } & \multicolumn{2}{|c|}{ Cephapirin } \\
\hline & & Broth & Serum & Broth & Serum & Broth & Serum & Broth & Serum \\
\hline S. aureus & 25 & 0.8 & 1.6 & 0.4 & 1.6 & 0.8 & 1.6 & 0.4 & 0.4 \\
\hline E. coli & 25 & 0.4 & 0.8 & 1.6 & 6.3 & 6.3 & 25 & 12.5 & 25 \\
\hline P. mirabilis & 22 & 2.4 & 3.2 & 4.7 & 25 & 3.2 & 6.3 & 6.3 & 6.3 \\
\hline K. pneumoniae & 25 & 0.8 & 1.6 & 1.6 & 6.3 & 3.2 & 12.5 & 3.2 & 6.3 \\
\hline E. aerogenes & 19 & 1.6 & 6.3 & 6.3 & 25 & 25 & 100 & 25 & 100 \\
\hline
\end{tabular}

* Mueller-Hinton Broth with $\sim 1 \times 10^{5} \mathrm{CFU} / \mathrm{ml}$ test medium. 
Cefazafiur activity against the most common gram-negative bacteria also was of high order. Cefazaflur was clearly more active than cefazolin, cephalothin and cephaloridine against Escherichia coli, Klebsiella pneumoniae and Proteus mirabilis (Figs. 2, 3, 4). In addition, cefazaflur was active against Enterobacter species whereas cephalothin and cephaloridine were inactive against these bacteria (Fig. 5) and cefazolin was active only against Enterobacter aerogenes (Table 1). Against indole-positive Proteus, Citrobacter, Herellea and Providencia none of the cephalo-
Fig. 6. Effect of human serum on the in vitro activity of selected cephalosporins against 25 clinical isolates of Staphylococcus aureus

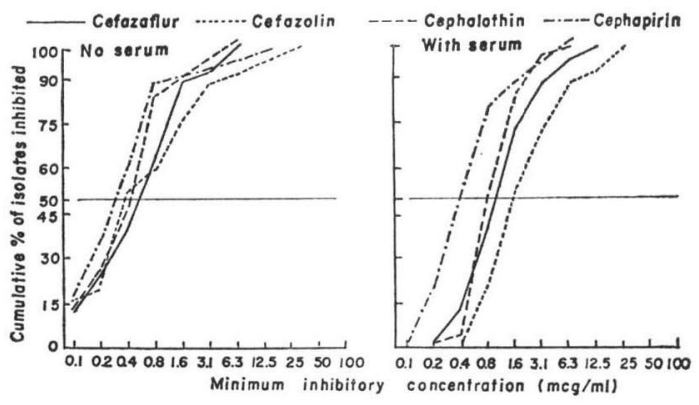
sporins tested showed significant activity, however, cefazaflur was active against some of the strains tested. These data are in general agreement with the recent report of VERBIST, although he reported a higher percentage of the indole-positive Proteus and Providencia strains to be susceptible to cefazaflur. ${ }^{11}$

A series of studies which are summarized in Table 2, were then carried out to examine the effect of human serum on the activity of cefazaflur and control cephalosporins. Fig. 6 shows the activity

Fig. 7. Effect of human serum on the in vitro activity of selected cephalosporins against 25 clinical isolates of Escherichia coli

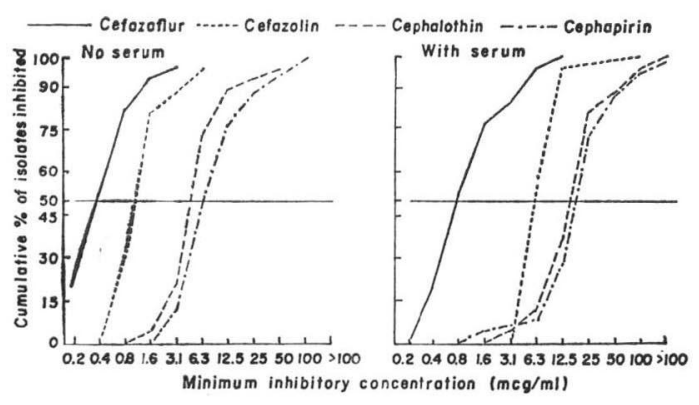

Fig. 9. Effect of human serum on the in vitro activity of selected cephalosporins against 22 clinical isolates of Proteus mirabilis

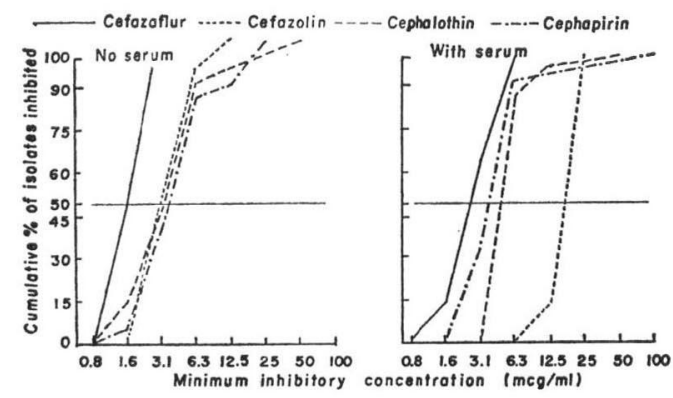

Fig. 8. Effect of human serum on the in vitro activity of selected cephalosporins against 25 clinical isolates of Klebsiella pneumoniae

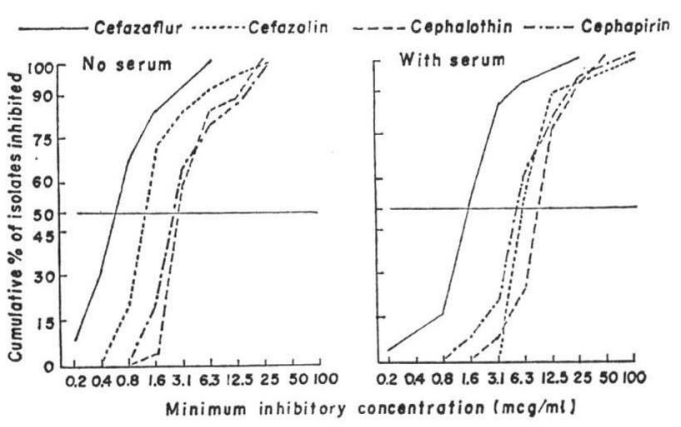

Fig. 10. Effect of human serum on the in vitro activity of selected cephalosporins against 19 clinical isolates of Enterobacter aerogenes

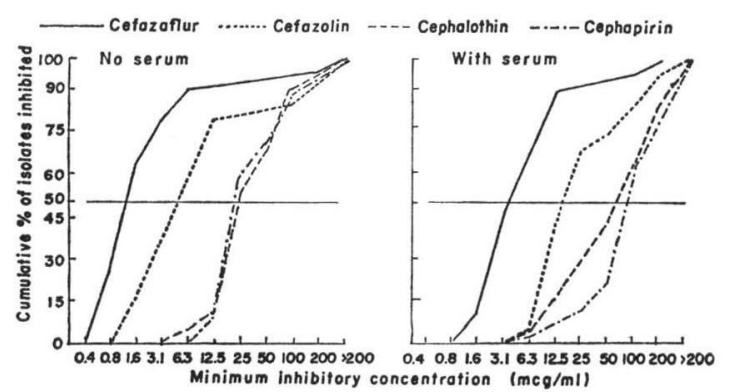


Table 3. Effect of inoculum size on in vitro activity of selected cephalosporins

\begin{tabular}{l|c|c|c|c|c|c|c|c|c}
\hline \multirow{2}{*}{ Cephalosporin } & \multicolumn{6}{c}{ Median minimum inhibitory concentration (mcg/ml) } \\
\cline { 2 - 11 } & \multicolumn{3}{|c|}{ Staph. aureus } & \multicolumn{3}{c|}{ E. coli } & \multicolumn{3}{c}{ Klebsiella } \\
\cline { 2 - 11 } & $10^{3}$ & $10^{5}$ & $10^{7}$ & $10^{3}$ & $10^{5}$ & $10^{7}$ & $10^{3}$ & $10^{5}$ & $10^{7}$ \\
\hline Cefazaflur & 0.4 & 0.8 & 3.1 & 0.4 & 0.4 & 6.3 & 0.2 & 0.4 & 1.2 \\
Cefamandole & 0.8 & 1.6 & 6.3 & 0.2 & 0.4 & 1.6 & 0.6 & 0.8 & 3.1 \\
Cephalothin & 0.4 & 0.4 & 1.6 & 3.1 & 6.3 & 50 & 1.6 & 2.4 & 12.5 \\
Cefazolin & 0.8 & 1.6 & 6.3 & 1.6 & 1.6 & 3.1 & 0.8 & 1.6 & 3.1 \\
Cefoxitin & 3.1 & 3.1 & 3.1 & 3.1 & 3.1 & 6.3 & 2.4 & 3.1 & 4.7 \\
Cefuroxime & 1.6 & 1.6 & 1.6 & 3.1 & 3.1 & 6.3 & 1.2 & 1.6 & 3.1 \\
Cephapirin & 0.4 & 0.4 & 3.1 & 3.1 & 6.3 & 100 & 1.2 & 1.6 & 12.5 \\
\hline
\end{tabular}

Table 4. Effect of inoculum size on in vitro activity of selected cephalosporins

\begin{tabular}{l|r|r|r|r|r|r|r|r}
\hline \multirow{2}{*}{ Cephalosporin } & \multicolumn{6}{|c}{ Median minimum inhibitory concentration (mcg/ml) } \\
\cline { 2 - 10 } & \multicolumn{2}{|c|}{ Citrobacter } & \multicolumn{2}{|c}{ Proteus (indole-positive) } & \multicolumn{3}{|c}{ Enterobacter sp. } \\
\cline { 2 - 10 } & $10^{5}$ & $10^{7}$ & $10^{5}$ & $10^{7}$ & $10^{9}$ & $10^{4}$ & $10^{6}$ & $10^{8}$ \\
\hline Cefazafiur & 1 & 250 & 8 & 125 & 500 & 4 & 8 & 500 \\
Cefamandole & 1 & 63 & $<0.5$ & 1 & 125 & 4 & 4 & 63 \\
Cefoxitin & 16 & 32 & 2 & 2 & 8 & 63 & 63 & 125 \\
Cefuroxime & 4 & 32 & 4 & 8 & 125 & 4 & 8 & 31 \\
\hline
\end{tabular}

of these cephalosporins against 25 clinical isolates of S. aureus with and without $50 \%$ human serum in the medium. With the exception of cephapirin which showed only a slight loss in activity, all of the cephalosporins showed a 2 4-fold loss in activity in the presence of serum. A similar experiment employing $25 \mathrm{E}$. coli strains is shown in Fig. 7. Again, the activity of all of the cephalosporins was reduced in serum, however, the median MIC value for cefazaflur in serum $(0.8 \mathrm{mcg} / \mathrm{ml})$ was clearly superior to cefazolin $(6.3 \mathrm{mcg} / \mathrm{ml})$, cephalothin $(25 \mathrm{mcg} / \mathrm{ml})$ and cephapirin $(25 \mathrm{mcg} / \mathrm{ml})$. Against $P$. mirabilis and $K$. pneumoniae isolates, cefazolin and cephalothin showed a 4-fold loss in median MIC values whereas cefazaflur and cephapirin showed little or no change in activity (Figs. 8, 9), Of the four cephalosporins examined for serum effects against $E$. aerogenes, only cefazaflur and cefazolin showed significant activity (Fig. 10). Cefazaflur was clearly more active than cefazolin against E. aerogenes in both broth and serum. It is of interest to note that although cephalothin is less bound to serum proteins than is cefazolin $(65 \%$ vs. $85 \%)$, its activity in the presence of serum was poorer than that of cefazolin. Cephalothin has been reported to be degraded in vitro by human serum after incubation at $37^{\circ} \mathrm{C}^{8}$.

The effect of inoculum size on in vitro activity of cefazaflur and control cephalosporins was next examined. In these studies, 10 organisms each of S. aureus, E. coli, K. pneumoniae, indole-positive Proteus, Enterobacter species and Citrobacter at various inoculum sizes were tested against seven parenteral cephalosporins. Table 3 shows the results obtained with S. aureus, E. coli and K. pneumoniae isolates. Cefazaflur, cefamandole, cephalothin and cefazolin all experienced a 4-fold increase in the median MIC values against $S$. aureus when the inoculum size was increased from $10^{5}$ to $10^{7}$ organisms/ $\mathrm{ml}$. Cephapirin showed an 8-fold loss in activity but no significant inoculum effect was observed with cefoxitin or cefuroxime. Against E. coli, cefazaflur showed a significant activity loss at the high inoculum size and $6.3 \mathrm{mcg} / \mathrm{ml}$ were required to inhibit $50 \%$ of the isolates. The median MIC for cephalothin (50 
$\mathrm{mcg} / \mathrm{ml})$ and cephapirin $(100 \mathrm{mcg} / \mathrm{ml})$ at this high inoculum size also had increased significantly. Against Klebsiella isolates, there was less of an inoculum effect; however, the MIC values for cephalothin and cephapirin at an inoculum size of $10^{7}$ organisms $/ \mathrm{ml}$ was relatively poor $(12.5 \mathrm{mcg} / \mathrm{ml})$.

A more dramatic effect of inoculum size was observed with organisms that tend to show a variable response to the newer cephalosporins (Table 4). Against these bacterial isolates (Citrobacter, indolepositive Proteus and Enterobacter sp.), cefazaflur showed good median MIC values at inoculum sizes ranging for $10^{4}$ to $10^{6}$ organisms $/ \mathrm{ml}$. At an inoculum level of $10^{7}$ organisms $/ \mathrm{ml}$, cefazaflur showed poor activity against strains of indole-positive Proteus and similar poor activity at $10^{8}$ organisms $/ \mathrm{ml}$ against Enterobacter species. Cefamandole showed a similar inoculum response but tended to be more active than cefazaflur against these organisms. Cefoxitin shows very little change in activity with increased inoculum size but was generally poor against the Enterobacter species. Cefuroxime was intermediate in response between cefoxitin and cephamandole, but, some break in activity was observed at the higher inoculum size especially against isolates of indole-positive Proteus. CounTs recently reported a similar high inoculum effect with indole-positive Proteus and Enterobacter species $^{5)}$.

Acknowledgements

We wish to thank MARIE KNIGHT and JoAN O'LeARY for their excellent technical assistance.

\section{References}

1) Actor, P.; J. Uri, J. Guarini, I. Zajac, J. Phillips, C. Sachs, R. DeMarinis, J. R. E. Hoover \& J. A. WeIsBACH: A new parenteral cephalosporin. SK\&F 59962: In vitro and in vivo antibacterial activity and serum levels in experimental animals. J. Antibiotics 28: 471 476, 1975

2) Actor, P.; J. Guarini, J. URi, R. Bartus, I. ZajaC \& J. A. Weisbach: In vitro studies with cefazaflur (SK\&F 59962), a new parenteral cephalosporin. Presented at 16th Interscience Conference on Antimicrobial Agents and Chemotherapy, Chicago, No. 89, 1976

3) Actor, P.; D. Pitkin, G. Lucyszyn, J. A. Weisbach \& J. Bran: A new parenteral cephalosporin. SK\&F 59962: Serum levels and urinary recovery in man. in Chemotherapy, Vol. 5, Penicillins and Cephalosporins, pp. 253 257, Plenum Press, New York, 1976

4) Bran, J. L.; P. Actor, D. H. Pitkin, G. Lucyszyn \& J. A. Weisbach: A new parenteral cephalosporin, SK\&F 59962: Human pharmacokinetics. Abstr. M-65, Proc. 9th Internat. Congr. Chemother., London, 1975

5) Counts, G.; D. Gregory, D. Zeleznik \& M. Turck: Cefazaflur, a new parenteral cephalosporin: In vitro studies. Antimicr. Agents \& Chemoth. 11: 708 711, 1977

6) Demarinis, R.; J. R. E. Hoover, G. Dunn, P. Actor, J. Uri \& J. A. Weisbach: A new parenteral cephalosporin. SK\&F 59962: 7-Trifluoromethylthioacetamido-3-(1-methyl-1H-tetrazol-5-ylthiomethyl)-3-cephem-4-carboxylic acid. Chemistry and structure activity relationships. J. Antibiotics 28: 463 470, 1975

7) Farrar, E. W. \& P. K. Gramling: Antistaphylococcal activity and $\beta$-lactamase resistance of newer cephalosporins. J. Infect. Dis. 133: 691 695, 1976

8) Fleming, P. C. \& B. Markowsky: A technique for measuring inhibitory concentrations of antibiotics in serum. Significance of protein binding of cephalosporins and serum inactivation of cephalothin. Presented at 15th Interscience Conferences on Antimicrobial Agents and Chemotherapy, Washington, No. 411, 1975

9) Harvengt, C.; H. Meunier \& F. Lamy: Pharmacokinetic study of cefazaflur compared to cephalothin and cefazolin. J. Clin. Pharmacol. 17: 128 133, 1977

10) Sutter, V. L. \& S. M. Finegold: Susceptibility of anaerobic bacteria to 23 antimicrobial agents. Antimicr. Agents \& Chemoth. 10: 736 752, 1976

11) Verbist, L.: Comparison of the antibacterial activity of nine cephalosporins against Enterobacteriaceae and non-fermentative Gram-negative bacilli. Antimicr. Agents \& Chemoth. 10: 657 663, 1976 